\title{
To contrast and reverse skeletal muscle weakness by Full-Body In- Bed Gym in chronic COVID-19 pandemic syndrome
}

\author{
Ugo Carraro (1-3), Giovanna Albertin (2,4), Alessandro Martini (5,6), Walter Giuriati (1), Diego \\ Guidolin (4), Stefano Masiero (2,7), Helmut Kern (8,9), Christian Hofer (9), Andrea Marcante \\ (10), Barbara Ravara (1-4)
}

(1) Department of Biomedical Sciences, University of Padova, Italy; (2) CIR-Myo Interdepartmental Research Center of Myology, University of Padova, Italy; (3) A\&C M-C Foundation for Translational Myology, Padova, Italy; (4) Department of Neuroscience, Section of Human Anatomy, University of Padova, Italy; (5) Department of Neuroscience, University of Padova, Italy; (6) Padova University Research Center "I Approve", University of Padova, Italy; (7) Department of Neuroscience, Section of Rehabilitation, University of Padova, Italy; (8) Ludwig Boltzmann Institute for Rehabilitation Research, St. Pölten, Austria; (9) Physiko- und Rheumatherapie, St. Pölten, Austria; (10) UOC Recovery and Functional Rehabilitation, Lonigo Hospital, Azienda ULSS 8 Berica, Lonigo, Italy.

This article is distributed under the terms of the Creative Commons Attribution Noncommercial License (CC BY-NC 4.0) which permits any noncommercial use, distribution, and reproduction in any medium, provided the original author(s) and source are credited.

\begin{abstract}
Mobility-impaired persons, either very old or younger but suffering with systemic neuromuscular disorders or chronic organ failures, spend small amounts of time for daily physical activity, contributing to aggravate their poor mobility by resting muscle atrophy. Sooner or later the limitations to their mobility enforce them to bed and to more frequent hospitalizations. We include among these patients at risk those who are negative for the SARSCOV-2 infection, but suffering with COVID-19 pandemic syndrome. Beside managements of psychological symptoms, it is mandatory to offer to the last group physical rehabilitation approaches easy to learn and self-managed at home. Inspired by the proven capability to recover skeletal muscle contractility and strength by home-based volitional exercises and functional electrical stimulation, we suggest also for chronic COVID-19 pandemic syndrome a 10-20 min long daily routine of easy and safe physical exercises that can activate, and recover from weakness, the main 400 skeletal muscles used for every-day mobility activities. Persons can do many of them in bed (Full-Body in-Bed Gym), and hospitalized patients can learn this light training before leaving the hospital. It is, indeed, an extension of well-established cardiovascularrespiratory rehabilitation training performed after heavy surgical interventions. Blood pressure readings, monitored before and after daily routine, demonstrate a transient decrease in peripheral resistance due to increased blood flow of many muscles. Continued regularly, Full-Body in-Bed Gym may help maintaining independence of frail people, including those suffering with the COVID-19 pandemic syndrome.
\end{abstract}

Key Words: skeletal muscle weakness; home-based Full-Body in-Bed Gym; older olds; borderline mobility impaired persons; COVID-19 pandemic syndrome.

Eur J Transl Myol 31 (1): 9641, 2021 doi: 10.4081/ejtm.2021.9641

There are about 700 named skeletal muscles in the human body, including 400 that are important only for medical specialists. Better known are the roughly 200 skeletal muscles that are serious bone-movers, plus another 100 little muscles of hands, feet, and face. The aim of this report is to convince persons-in-need, and their practitioners, to counteract muscle atrophysarcopenia-cachexia, maintaining at their best function and shape of the majority of their body muscles. ${ }^{1}$ Geriatric subjects, due to advanced age and/or associated diseases, spend only a short amount of time for daily physical activity. The consequent disuse muscle atrophy contributes to limit their independence ultimately enforcing them to bed and to hospitalization for long periods. Low mobility-related muscle atrophy is associated with neuromuscular weakness, functional limitations, thromboembolism, and high costs. ${ }^{2-4}$ All 


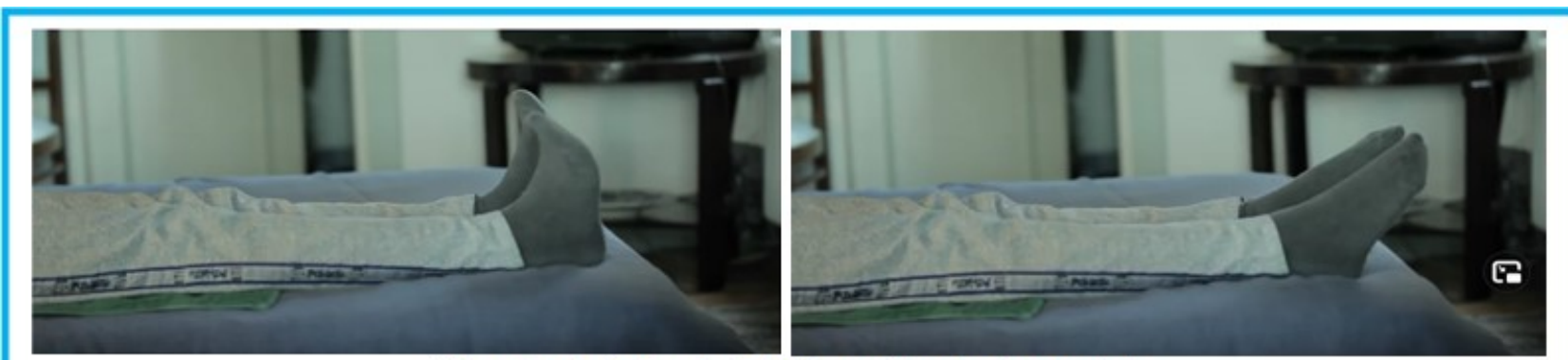

Exercise 1: Lying in bed, flex and extend your feet
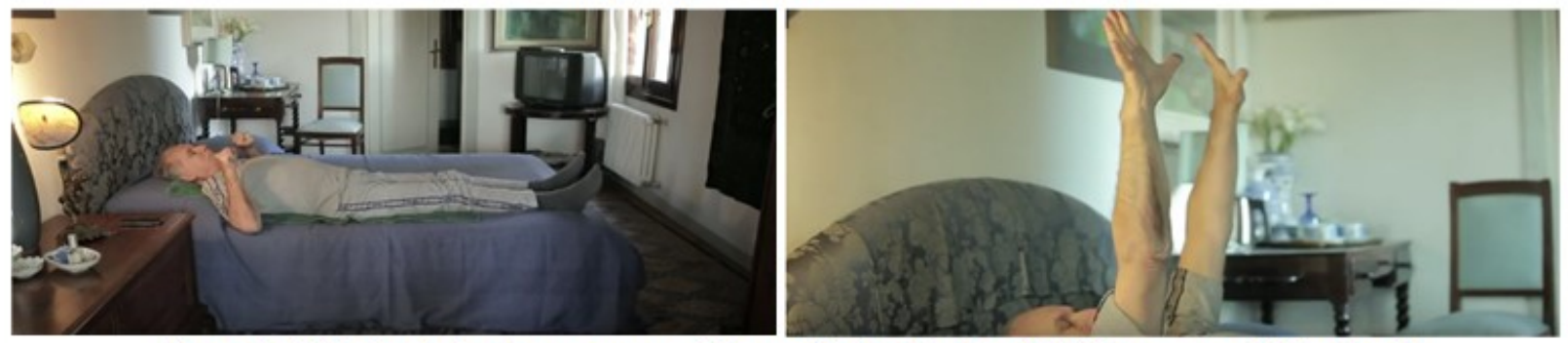

Exercise2: Lying in bed, arms up and down. Notice the hands fully open or fully closed
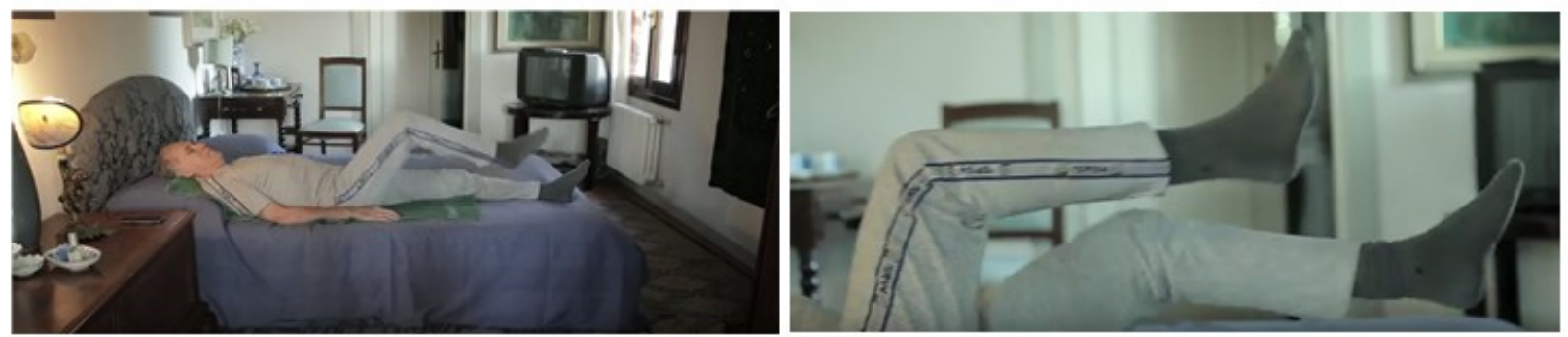

Exercise 3: Lying in bed, cycling movements of legs
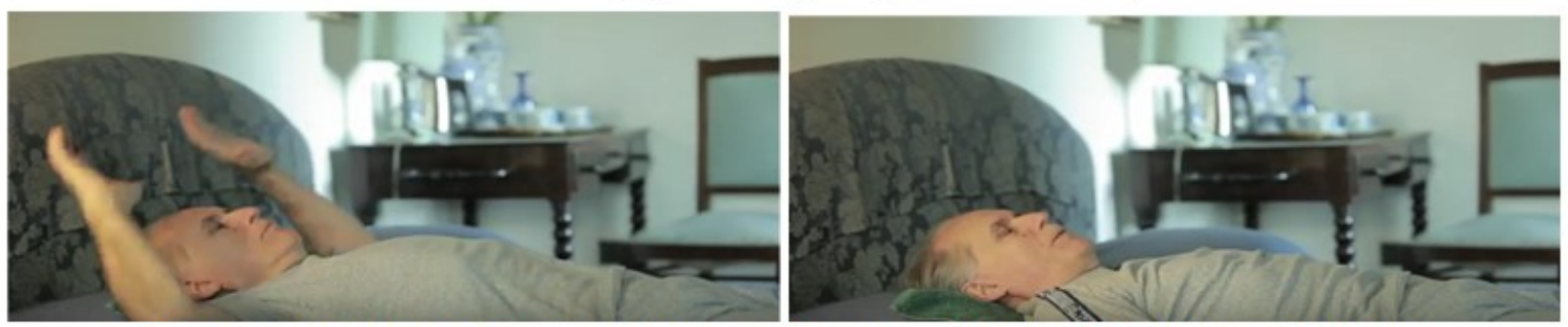

Exercise 4: Lying in bed, deep breathings, raising arms and open hands during inspiration
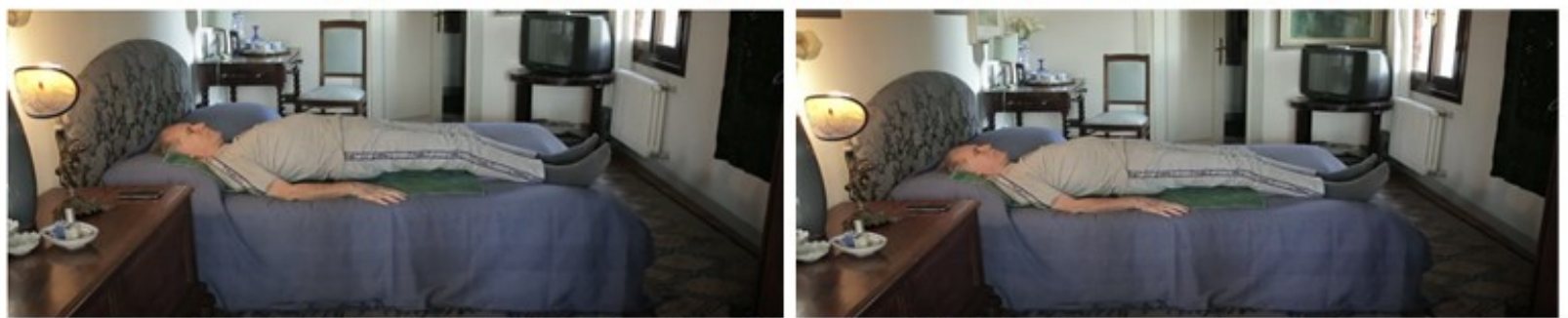

Exercise 5: Lying in bed, raising the pelvis and maintaining the up position for $2 \mathrm{sec}$.

Fig 1. The puppose of the routine is to contract all major skeletal muscles, alternating exercises to mobilize arms and legs, spine and neck, diaphragm and accessory ventilation muscles Duration of the routine (i.e., the number of repetitions and subsequently their speed of execution) must always reach the fatigue threshold.

progressive muscle contractile impairments need permanent management. Besides eventual pharmacological treatment, a home-based physical exercise approach is helpful in counteracting muscle atrophy. Awaiting development of implantable devices for muscle stimulation, as effective as pacemakers for cardiac arrhythmias, ${ }^{5}$ implantable stimulators for ventilatory supports, ${ }^{6,7}$ or cochlear implants for hearing 


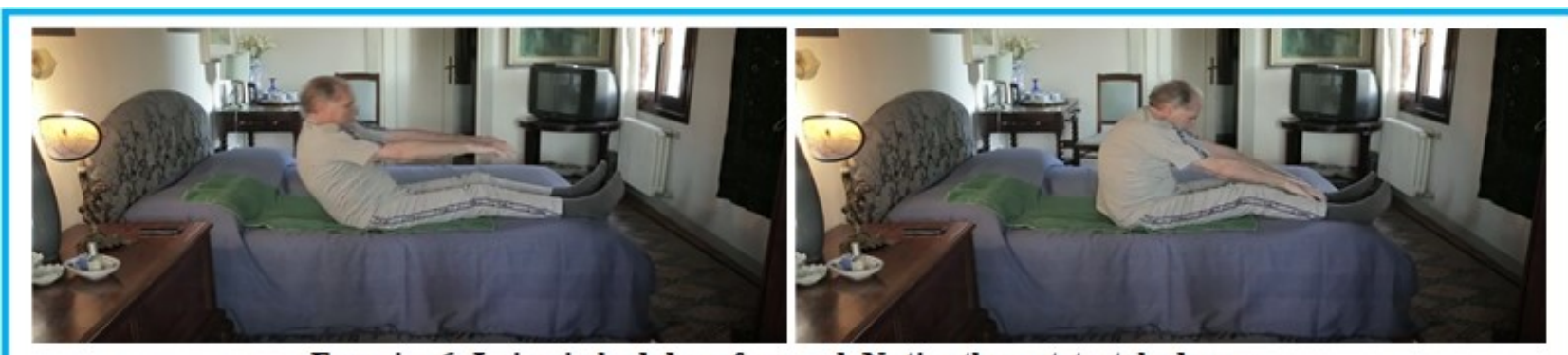

Exercise 6: Lying in bed, lean forward. Notice the outstretched arms.

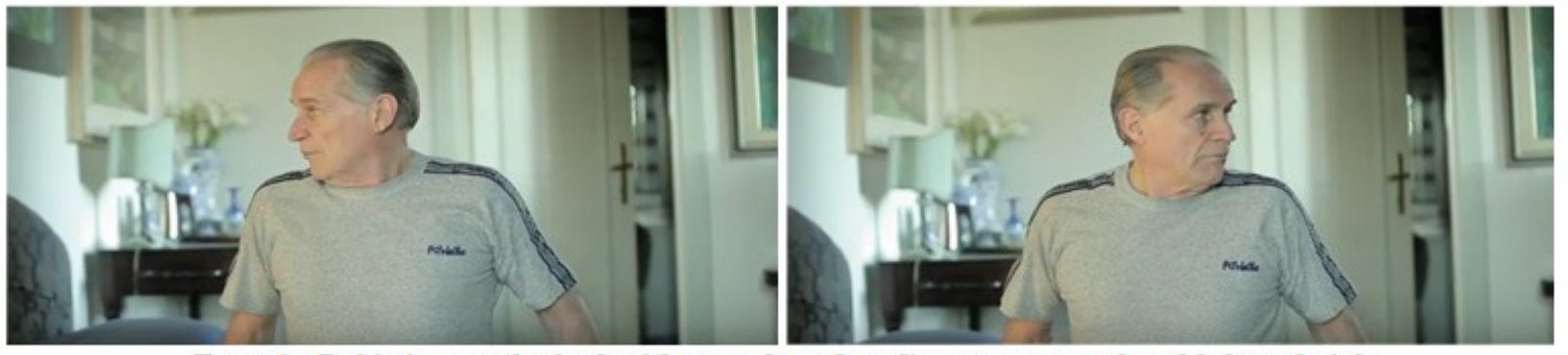

Exercise7: Sitting on the bed with your legs dangling, turn your head left and right
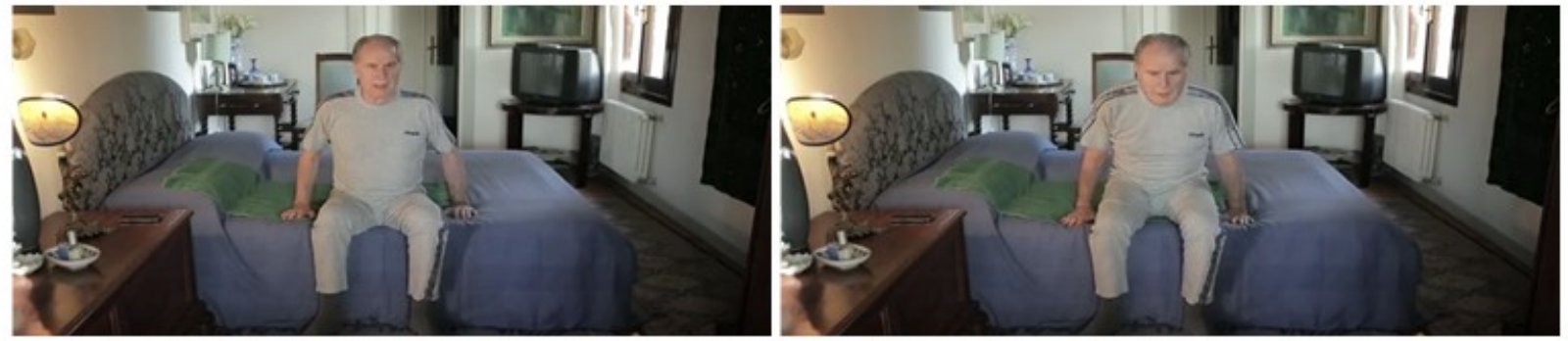

Exercise 8: Sitting on the bed with your legs dangling, lift your body up with your arms

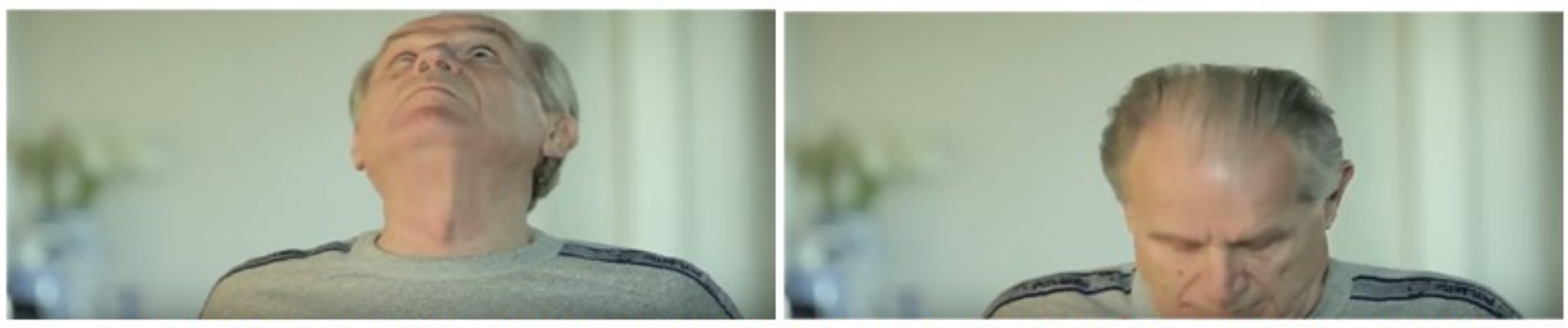

Exercise 9: Sitting on the bed with your legs dangling, bend your head and trunk back and forth
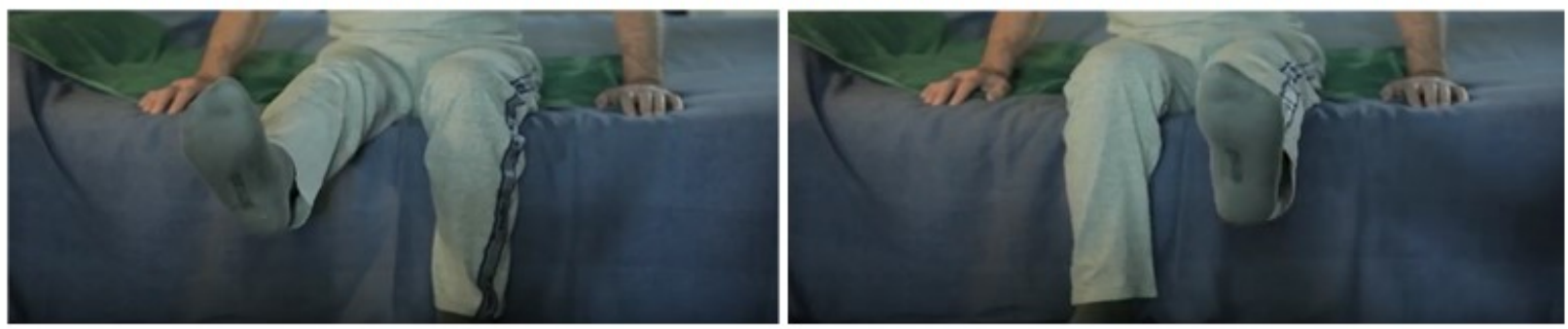

Exercise 10: In a seated position, alternately raise one thigh and fully extend the leg.

Fig 2. The aim of the routine is to contratc all main skeletal muscles, alternating exercises to mobilize anms and legs, spinal cord and neck, diaphragm and ventilation accessory muscles. Intensity of the routine (as number of repetitions and then speed) must be up to fatigue threshold.

loss, ${ }^{8,9}$ education of sedentary patients to perform home physical exercises could be an effective low-cost alternative during and after hospitalization. ${ }^{10-12}$
Cardiovascular and respiratory physical rehabilitation protocols of surgical patients are well established approaches, whose main goal is to reverse muscle weakness/atrophy. ${ }^{13,14}$ We extended those routines to a 
Full-Body in-Bed Gym for prevention and recovery of COVID pandemic syndrome

Eur J Transl Myol 31 (1): 9641, 2021 doi: 10.4081/ejtm.2021.9641

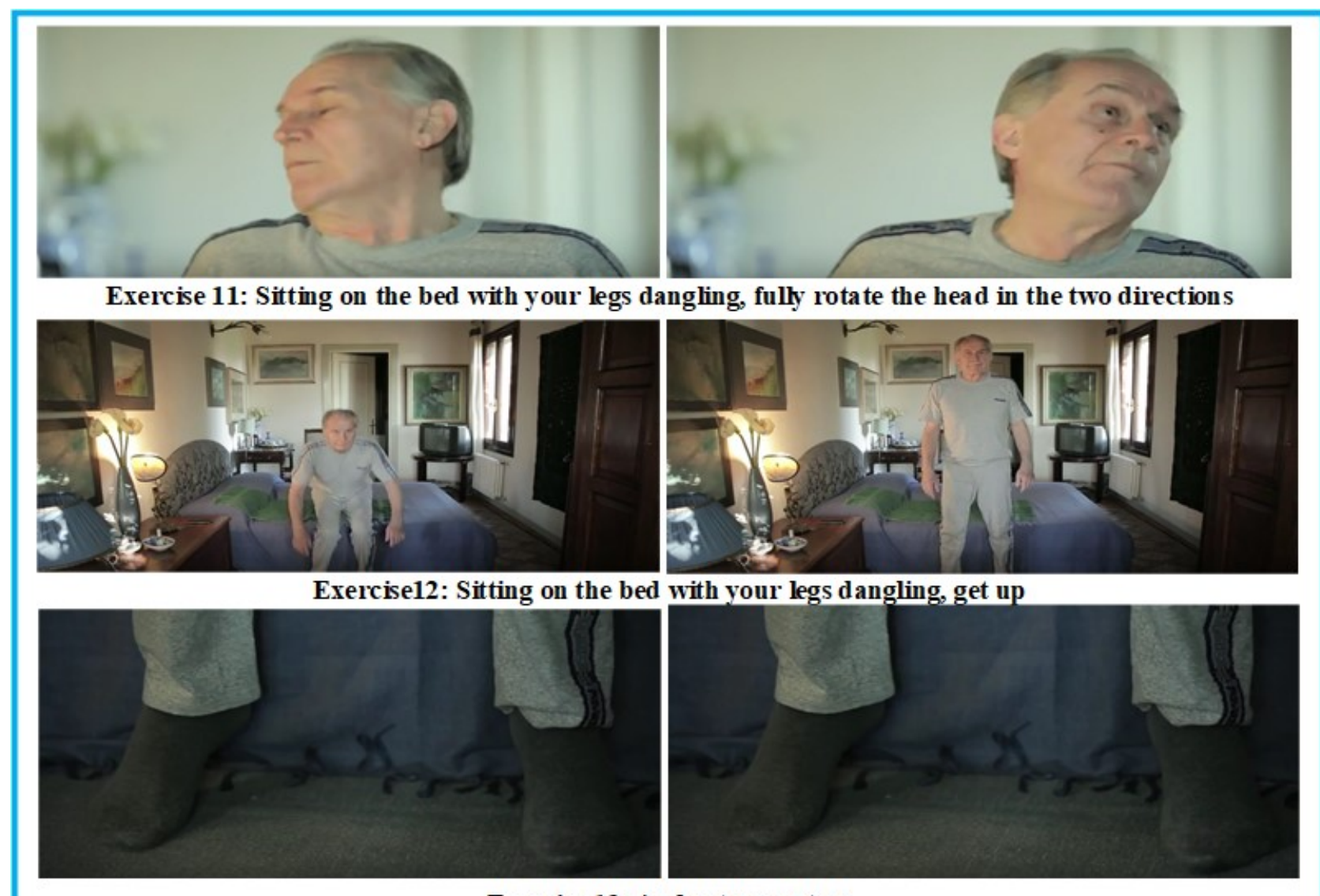

Exercise 13: And get up on toes

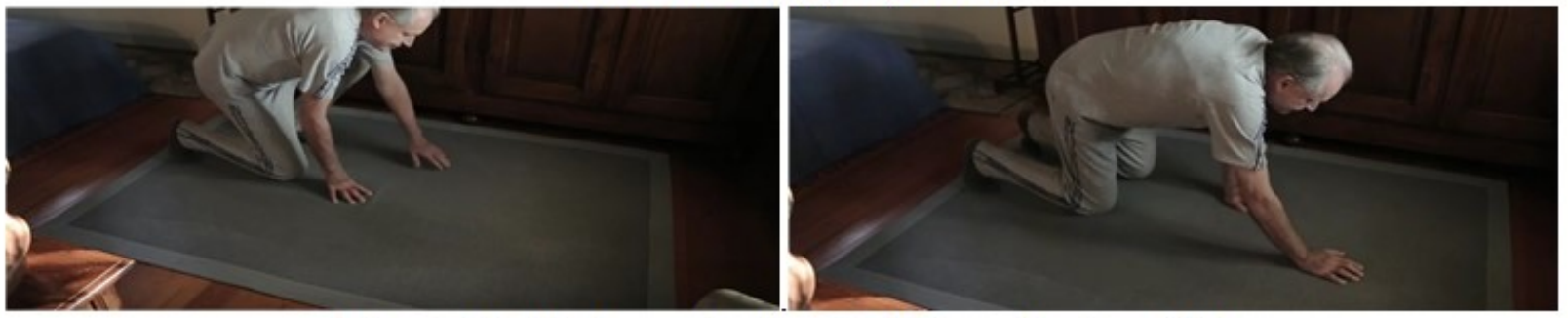

Exercise 14: Lie down and get up slowly to avoid ruinous falls
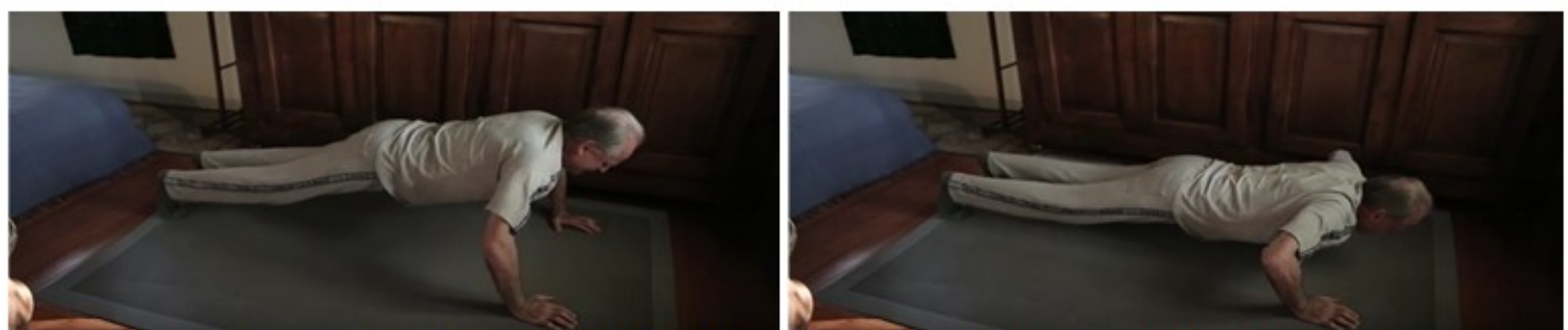

Exercise 15: For active people only, push-ups performed as the last exercise. To increase its effectiveness, keep the down flexion until the sweat of the forehead is visible and collectable

Fig 3. The aim of the routine is to contratc all main skeletal muscles, alternating exercises to mobilize arms and legs, spinal cord and neck, diaphragm and ventilation accessory muscles. Intensity of the routine (as number of repetitions and then speed) must be up to fatigue threshold.

daily short (10-20 min) sequence of easy-to-learn and safe volitional physical exercises to be performed in bed (Full-Body in-Bed Gym) to improve muscles and, hence, mobility of impaired persons.
Chronic COVID-19 pandemic syndrome is characterized by the psychological response to the global problem of COVID-19 pandemic, and often by muscle weakness that negatively influences the quality of life of persons for 
weeks or months before or after resolution of the infection. ${ }^{15-17}$ This syndrome is believed to affect up to $10 \%$ of the population, because it could already be observed as an acute stress reaction to the spread of the SARS-CoV-2 infection. Certainly it changes in people the ordinary lifestyle for the forced lockdown measures imposed to control the epidemics. ${ }^{18,19}$ However, the most severe responses are expected later on after recovering COVID-19. In this case the pandemic syndrome is similar to post-traumatic stress disorders. The problem is that pandemic syndrome will affect the working capacity of population even when economic recovery will be possible and essential. Adequate prophylaxis and management of the syndrome in high-risk groups are important for maintaining global mental health and economy. Beside pharmacological support and psychotherapy in the acute phases, it will be mandatory to prevent and control the mild cases by general prophylactic measures and healthy lifestyle, i.e., by normalization of sleep-wake schedule, by controlling dietary intake of vitamins and microelements and by inducing moderate physical activity. All these measures are important to maintain a good physical condition that improves body adaptive potentials and the immune system.

Here our contribution is to convince practitioners, ${ }^{20-23}$ and the population at large that Full-Body in-Bed Gym is an option to be taken seriously, despite its apparent minimal requested effort. ${ }^{10-12}$
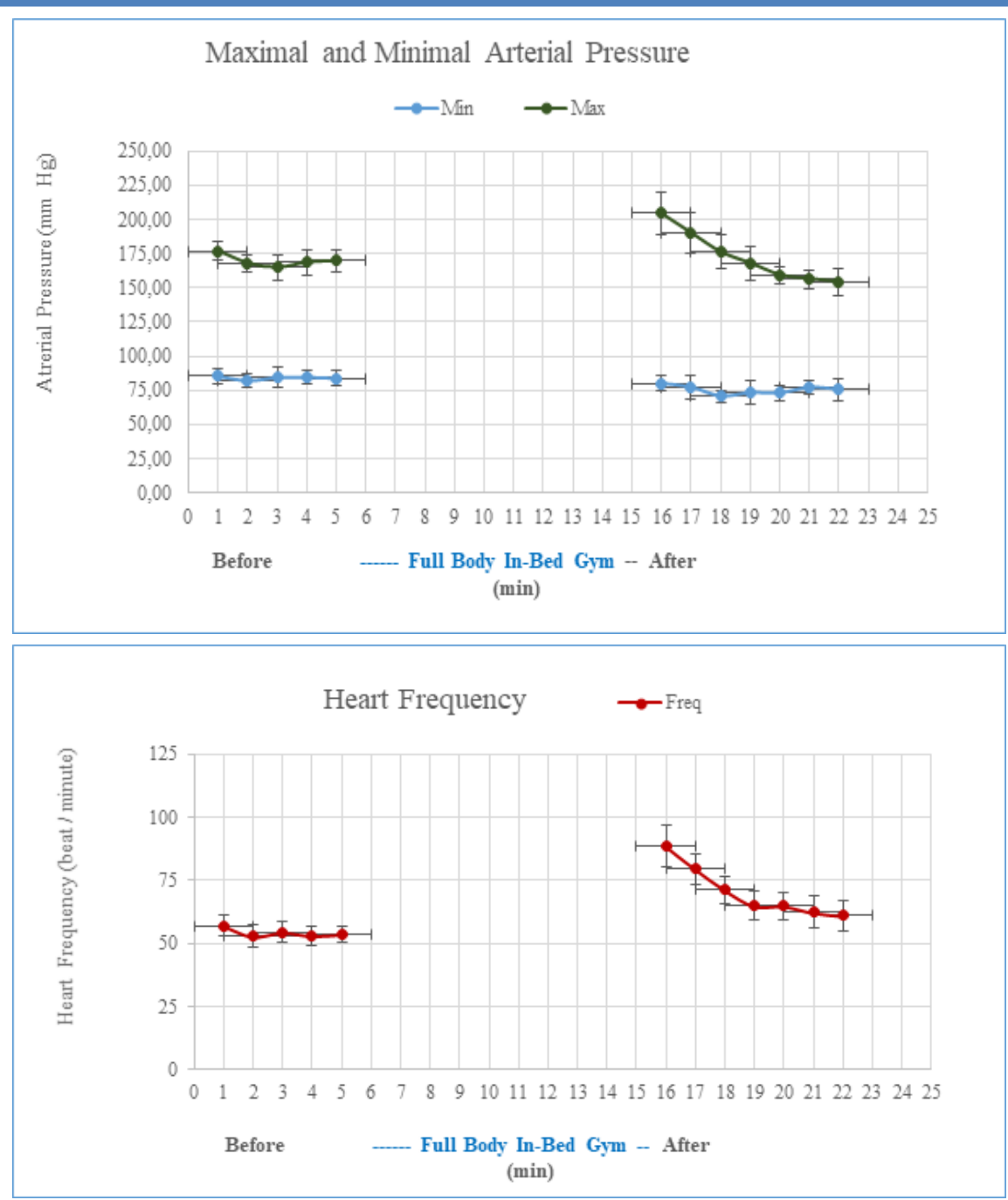

Fig 4. Arterial pressure and cardiac frequency before and after 10 minutes of Full Body in-Bed Gym (25 repetitions of each exercise, including push-up) during seven consecutive days (November 8 to 14, 2016). Mean +/$S D$. After a self-challenging routine, cardiac and ventilatory frequency increased together with the maximal, but not the minimal arterial pressure. Indeed, the latter is more related to peripheral blood resistance. The exercise-induced increase of blood perfusion of all the main skeletal muscle of the body occurs if the series of exercise reach the level of fatigue threshold. 


\section{Suggested workout}

In Figures 1, 2 and 3, the Exercises 1 to 14 show the routine that could be a seasonal warm up also for active persons (typically at early spring after a long winter to recover fitness for demanding physical activities), i. e, those able to make at least 20 consecutive push-ups in 3 min (Figure 3, Exercise 15). After advice of his/her family physician to avoid the very low risks of exercise pain and eventual muscle and joint damage, any sedentary people may start with five repetitions of each exercise. After one-two weeks of training, they may add groups of five additional repetitions, up to 30, every additional week. If compliant, even older olds will progressively increase their muscle strength, if they reach and maintain 15 or 20 daily repetitions. It is safer to start performing the exercises at very slow speed, but when the maximum number of each exercise is reached (15 or 20 repetitions), improving effects will be obtained by speeding up each exercise and thus increasing intensity. The daily routine may last from $10 \mathrm{~min}$ (in the beginning) to $30 \mathrm{~min}$ (for complete session in accustomed persons). Figures 1, 2 and 3, show the exercises and the captions provide some details.

A video, ${ }^{24}$ describes them dynamically: https://www.youtube.com/watch?v=N1RuG3371-

Y\&feature=youtu.be

If sedentary persons without major comorbidities, but with rest-related muscle weakness, avoiding much stress, challenge themselves in a few weeks of Full-Body in-Bed Gym may increase their muscle strength, fatigue resistance and independence in daily life activities.

Cautious Full-Body in-Bed Gym may help patients to recover earlier after hospitalization, decreasing the risk of thromboembolism after surgical interventions, and concurring to reduce eventual arterial hypertension. ${ }^{25}$ Indeed, after a routine that challenge personal fitness, $i$. e., like inducing sweat to the forehead, increasing cardiorespiratory rates, and maximal, but not minimal blood pressure, in a few minutes the increased values return to the pre-exercise values, as the minimal arterial pressure. One example of those behaviors of the cardiovascular responses to a challenging series of a week of trainings are exemplified in Figure 4. There is strong evidence that peripheral arterial resistance decreased during the series of challenging exercises because blood perfusion is increased by relaxation of the perforating arteries of the main skeletal muscles of the body, i.e. for the systemic functional hyperemia of the main body muscles. ${ }^{12}$

Furthermore, Full-Body in-Bed Gym routine mitigates the bad mood that is usually associated to mobility limitations, ${ }^{26,27}$ strengthening confidence of patient in recovering partial or total independence, and it reduces risks of accidental falls. Eventually, during hospitalizations the monitoring of the responses to challenging trainings could include oxygen saturation and many more fitness variables. Furthermore to speedup positive changes, the trainings could be performed twice a day to improve fatigue resistance and cardio- respiratory reserve. ${ }^{28,29}$ Wearable devices are an emerging and cost-effective technology that allows to monitor several biometric data, ${ }^{30}$ and have been tested in many diseases. ${ }^{31}$ It might be interesting to add one of these devices (e.g. smartwatches, fitbands, smartphones, etc.) which could represent a guide for the patient during workout (heart rate monitoring and oxyhemoglobin saturation, reminder to perform exercises every day, stopwatch for timing her/his workout. ${ }^{32}$ In any case, during the initial learning period of Full Body In-bed Gym, all seniors, if not hospitalized, must be supervised by at least one trainer, if not a health professional to avoid harmful exercise. These, in fact, are linked to their fitness and, nothing to say, to comorbidities often present in elderly population. If elderly persons cannot, or are reluctant to perform volitional physical rehabilitation protocols, functional electrical stimulation may mimic those exercises and be almost equally effective. ${ }^{33-41}$ As detailed in Kern et al., in 2014, ${ }^{36}$ old persons may be exposed to regular neuromuscular electrical stimulation training. Stimulators for surface electrical stimulation (ES) that are especially suited for elderly people requirements were designed and implemented in Vienna, Austria. ${ }^{42}$ These constant voltage stimulation devices can be safely applied during home use. Starting two times a week, for a total amount of 24 training sessions $(3 \times 10$ minutes for each session) ES is safe and effective. The subjects ought to be instructed to increase the stimulation intensity until their maximal tolerance is reached. Using this approach a full knee extension is achieved in all subjects. The outcome is a significant increase in muscle strength, associated with an increase of fast muscle fibers, which are the first to respond to ES and are well related to the power of skeletal muscle. ES significantly increased the size of fast type muscle fibers, and the number of Pax7- and NCAM-positive satellite cells. Moreover, analyzed muscle biopsies did not presented signs of muscle damage and/or cellular inflammation. ${ }^{36,43}$ Altogether, previous results demonstrated that physical exercise, either voluntary or induced by electrical stimulation, improves the functional performance of skeletal muscles, including those essential for ventilation, a main problem in COVID-19 patients. Indeed, it is worth noting that one of the most successful clinical application of skeletal muscles ES is the ventilatory support to person-in-need by pacing of a conditioned diaphragm in quadriplegia and beyond. ${ }^{6,7,44-47}$ In conclusion, it is never too early and it is never too late to increase daily levels of volitional or FES-induced muscle contractions in aging and early-aging syndromes. ${ }^{19-22}$ Full-Body in-Bed Gym could help patients suffering with mild cases to prevent chronic COVID-19 syndrome and to recover from weakening of skeletal muscles.

\section{List of acronyms}

COVID-19 - Coronavirus disease 2019

FES - functional electrical stimulation

SARS - Severe Acute Respiratory Syndrome 


\section{Acknowledgments}

A\&C M-C Foundation for Translational Myology, Padova, Italy and PAGEpress, Scientific Publications, Pavia, Italy sponsored publication of this typescript.

\section{Funding None}

\section{Conflict of Interest}

The authors declare no competing interests.

\section{Ethical Publication Statement}

Authors confirm that they have read the Journal's position on issues involved in ethical publication and affirm that this report is consistent with those guidelines.

\section{Corresponding Author}

Barbara Ravara, Department of Biomedical Sciences, Via Ugo Bassi, 58/B - Padova, Italy. ORCID iD: 0000-0002-0159-3245

E-mail: barbara.ravara@unipd.it

\section{E-mail and ORCID of co-authors}

Ugo Carraro: ugo.carraro@unipd.it ORCID iD: 0000-0002-0159-3245

Giovanna Albertin: giovanna.albertin@unipd.it ORCID iD: 0000-0002-7551-4431

Alessandro Martini: alessandromartini@unipd.it ORCID iD: 0000-0002-2003-6348

Stefano Masiero: stef.masiero@unipd.it

ORCID iD: 0000-0002-0361-4898

Helmut Kern: helmut@kern-reha.at

ORCID iD: 0000-0001-9661-8814

Christian Hofer:

$$
\text { christian.hofer@rehabilitation.lbg.ac.at }
$$

ORCID iD: 0000-0001-5767-3423

Andrea Marcante: andrea.marcante@aulss8.veneto.it ORCID iD: 0000-0002-0869-6175

Walter Giuriati: walter.giuriati@unipd.it

ORCID iD: 0000-0002-9991-3488

\section{References}

1. Gava P, Kern H, Carraro U. Age-associated power decline from running, jumping, and throwing male masters world records. Exp Aging Res. 2015;41(2):115-35. doi: 10.1080/0361073X.2015. 1001648.

2. Hopkins RO, Mitchell L, Thomsen GE, Schafer M, Link M, Brown SM. Implementing a mobility program to minimize post-intensive care syndrome. AACN Adv Crit Care. 2016 Apr-Jun;27(2):187203. doi: 10.4037/aacnacc2016244.

3. Camillo CA, Osadnik CR, van Remoortel H, Burtin C, Janssens W, Troosters T. Effect of "add-on" interventions on exercise training in individuals with COPD: a systematic review. ERJ Open Res. 2016 Mar 29;2(1):00078-2015. doi: 10.1183/23120541.00078-2015.

4. Czyrny JJ, Kaplan RE, Wilding GE, Purdy CH, Hirsh J. Electrical foot stimulation: a potential new method of deep venous thrombosis prophylaxis. Vascular. Jan-Feb 2010;18(1):20-7. doi: 10.2310/ 6670.2010.00001. Erratum in Vascular $2010 \mathrm{Mar}-$ Apr;18(2):121.

5. Saleem-Talib S, van Driel VJ, Chaldoupi SM, Nikolic T, van Wessel H, Borleffs CJW, Ramanna H. Leadless pacing: Going for the jugular. Pacing Clin Electrophysiol. 2019 Apr;42(4):395-399. doi: 10.1111/pace.13607. Epub 2019 Feb 25.

6. Glenn WW, Hogan JF, Loke JS, Ciesielski TE, Phelps ML, Rowedder R. Ventilatory support by pacing of the conditioned diaphragm in quadriplegia. N Engl J Med. 1984 May 3;310(18):1150-5. doi: 10.1056/NEJM1984050 33101804.

7. Skalsky AJ, Lesser DJ, McDonald CM. Evaluation of phrenic nerve and diaphragm function with peripheral nerve stimulation and M-mode ultrasonography in potential pediatric phrenic nerve or diaphragm pacing candidates. Phys Med Rehabil Clin N Am. 2015 Feb;26(1):133-43. doi: 10.1016/j.pmr.2014.09.010.

8. Eskridge HR, Park LR, Brown KD. The impact of unilateral, simultaneous, or sequential cochlear implantation on pediatric language outcomes. Cochlear Implants Int. 2021 Jan 12:1-8. doi: $10.1080 / 14670100.2020 .1871267$. Online ahead of print.

9. Gallo S, Trevisi P, Rigon C, Caserta E, Seif Ali D, Bovo R, Martini A, Cassina M. Auditory Outcome after Cochlear Implantation in Children with DFNB7/11 Caused by Pathogenic Variants in TMC1 Gene. Audiol Neurootol. 2020 Dec 22:1-7. doi: 10.1159/000510156. Online ahead of print.

10. Carraro U, Gava K, Baba A, Piccione F, Marcante A. Fighting muscle weakness in advanced aging by takehome strategies: Safe anti-aging full-body inbed gym and functional electrical stimulation (FES) for mobility compromised elderly people. Biol Eng Med. 2016;1:1-4. doi: 10.15761/BEM.1000106.

11. Carraro U, Gava K, Musumeci A, Baba A, Piccione F, Marcante A. Safe Antiaging Full-Body In-Bed Gym and FES for Lazy Persons: Home In-Bed Exercises for Fighting Muscle Weakness in Advanced Age. In: Rehabilitation Medicine for Elderly Patients, Masiero S, Carraro U, Eds., pag. 43-52. ISBN 978-3-319-57405-9 ISBN 978-3-31957406-6 (eBook). doi 10.1007/978-3-319-57406-6.

12 Carraro U, Gava K, Baba A, Marcante A, Piccione F. To Contrast and Reverse Skeletal Muscle Atrophy by Full-Body In-Bed Gym, a Mandatory Lifestyle for Older Olds and Borderline MobilityImpaired Persons. Adv Exp Med Biol. 2018;1088:549-560. doi: 10.1007/978-981-131435-3_25.

13. Ades PA, Keteyian SJ, Wright JS, Hamm LF, Lui K, Newlin K, Shepard DS, Thomas RJ. Increasing Cardiac Rehabilitation Participation From 20\% to 
70\%: A Road Map From the Million Hearts Cardiac Rehabilitation Collaborative. Mayo Clinic proceedings. 2017;92(2):234-242. doi: 10.1016/j. mayocp.2016.10.014. Epub 2016 Nov 15.

14. Vorona S, Sabatini U, Al-Maqbali S, Bertoni M, Dres M, Bissett B, Van Haren F, Martin AD, Urrea C, Brace D, Parotto M, Herridge MS, Adhikari NK, Fan E, Melo LT, Reid WD, Brochard LJ, Ferguson ND, Goligher EC. Inspiratory Muscle Rehabilitation in Critically Ill Adults: A Systematic Review and Meta-Analysis. Ann Am Thorac Soc. 2018 Jun;15(6):735-744. doi: 10.1513/AnnalsATS. 201712-961OC.

15. Soloveva NV, Makarova EV, Kichuk IV. Coronavirus syndrome: COVID-19 psychotrauma. Eur J Transl Myol. 2020; 30 (4): 9302. doi: 10.4081/ejtm.9302.

16. Mohsen Khosravi. COVID-19 quarantine: Twoway interaction between physical activity and mental health. Eur J Transl Myol. 2020; 30 (4): 9509. doi: 10.4081/ejtm.2020.9509.

17. Angelini C, Siciliano G. Neuromuscular diseases and Covid-19: Advices from scientific societies and early observations in Italy. Eur J Transl Myol. 2020 Jun 22;30(2):9032. doi: 10.4081/ejtm.2019.9032.

18. Moro T, Paoli A. When COVID-19 affects muscle: effects of quarantine in older adults. Eur J Transl Myol. 2020 Jun 17;30(2):9069. doi: 10.4081/ejtm.2019.9069. eCollection 2020 Jul 13. PMID: 32782767 Free PMC article.

19 O’Hara Jennifer. Rehabilitation after COVID-19. Mayo Clinic News Network. 2020 October 3. Available:

https://newsnetwork.mayoclinic.org/discussion/reh abilitation-after-covid-19/

20. Fiorenzato E, Zabberoni S, Costa A, Cona G. Cognitive and mental health changes and their vulnerability factors related to COVID-19 lockdown in Italy. PLoS One. 2021 Jan 27;16(1):e0246204. doi: 10.1371/journal.pone. 0246204. eCollection 2021.

21. Demeco N, Marotta M, Barletta I, Pino C, Marinaro A, Petraroli L, Moggio L, Ammendolia A. Rehabilitation of patients post-COVID-19 infection: a literature review. J Int Med Res. 2020 Aug;48(8):300060520948382. doi: 10.1177/03000 60520948382.

22 Wang TJ, Chau B, Lui M, Lam GT, Lin N, Humbert S. Physical Medicine and Rehabilitation and Pulmonary Rehabilitation for COVID-19. Am J Phys Med Rehabil. 2020 Sep;99(9):769-774. doi: 10.1097/PHM.0000000000001505.

23. Smith JM, Lee AC, Zeleznik H, Coffey Scott JP, Fatima A, Needham DM, Ohtake PJ. Home and Community-Based Physical Therapist Management of Adults With Post-Intensive Care Syndrome. Phys Ther. 2020 Jul 19;100(7):1062-1073. doi: 10.1093/ptj/pzaa059. PMID: 32280993; PMCID: PMC7188154.

24. Available:

https://www.youtube.com/watch?v=N1RuG3371Y\&feature=youtu.be

25. Börjesson M, Onerup A, Lundqvist S, Dahlöf B. Physical activity and exercise lower blood pressure in individuals with hypertension: narrative review of 27 RCTs. Br J Sports Med. 2016 Mar;50(6):35661. doi: 10.1136/bjsports-2015-095786. Epub 2016 Jan 19.

26. Carneiro LS, Fonseca AM, Serrão P, Mota MP, Vasconcelos-Raposo J, Vieira-Coelho MA. Impact of physical exercise on catechol-Omethyltransferase activity in depressive patients: a preliminary communication Affect Disord. 2016 Mar 15;193:117-22. doi: 10.1016/j.jad.2015.12. 035.

27. Simõe Seguro C, Silva Rebelo AC, Silva AG, Malaquias M, dos Santos A, Cardoso JS, Apolinário V, Veiga Jardim PC, Gentil P. Use of low volume, high effort resistance training to manage blood pressure in hypertensive patients inside a public hospital: a proof of concept study Eur J Transl Myol. Eur J Transl Myol. 31 (1): 9547, 2021 doi: 10.4081/ejtm.2021.9547

28. Masiero S, Maccarone MC, Agostini F. Health resort medicine can be a suitable setting to recover disabilities in patients tested negative for COVID19 discharged from hospital? A challenge for the future. Int J Biometeorol. 2020 Oct;64(10):18071809. doi: 10.1007/s00484-020-01947-4.

29. Masiero S, Zampieri D, Del Felice A. The Place of Early Rehabilitation in Intensive Care Unit for COVID-19. Am J Phys Med Rehabil. 2020 Aug;99(8):677-678. doi: 10.1097/PHM.000000000 0001478.

30. Khoshmanesh F, Thurgood P, Pirogova E, Nahavandi S, Baratchi S. Wearable sensors: At the frontier of personalised health monitoring, smart prosthetics and assistive technologies. Biosens Bioelectron. 2021 Mar 15;176:112946. doi: 10.1016/j.bios.2020.112946. Epub 2020 Dec 30.

31. Gatsios D, Antonini A, Gentile G, Marcante A, Pellicano C, Macchiusi L, Assogna F, Spalletta G, Gage H, Touray M, Timotijevic L, Hodgkins C, Chondrogiorgi M, Rigas G, Fotiadis DI, Konitsiotis S. Feasibility and Utility of mHealth for the Remote Monitoring of Parkinson Disease: Ancillary Study of the PD_manager Randomized Controlled Trial. JMIR Mhealth Uhealth. 2020 Jun 29;8(6):e16414. doi: 10.2196/16414.

32. Graña Possamai C, Ravaud P, Ghosn L, Tran VT. Use of wearable biometric monitoring devices to measure outcomes in randomized clinical trials: a methodological systematic review BMC Med. 2020 Nov 6;18(1):310. doi: 10.1186/s12916-020-01773W. 
33. Kern H, Carraro U, Adami N, Biral D, Hofer C, Forstner C, Mödlin M, Vogelauer M, Pond A, Boncompagni S, Paolini C, Mayr W, Protasi F, Zampieri S. Home-based functional electrical stimulation rescues permanently denervated muscles in paraplegic patients with complete lower motor neuron lesion. Neurorehabil Neural Repair. 2010 Oct;24(8):709-21. doi: 10.1177/1545968310 366129.

34. Carraro U, Kern H. Severely atrophic human muscle fibers with nuclear misplacement survive many years of permanent denervation. Eur J Transl Myol. 2016 Jun 13;26(2):5894. doi: 10.4081/ejtm. 2016.5894.

35. Carraro U, Kern H, Gava P, Hofer C, Loefler S, Gargiulo P, Mosole S, Zampieri S, Gobbo RB, Piccione P, Marcante A, Baba A, Schils S, Pond A, Gava F. Biology of muscle atrophy and of its recovery by FES in aging and mobility impairments: roots and by-products. Eur J Transl Myol. 2015 Aug 25;25(4):221-30. doi: 10.4081 /ejtm.2015.5272.

36. Kern H, Barberi L, Löfler S, Sbardella S, Burggraf S, Fruhmann H, Carraro U, Mosole S, Sarabon N, Vogelauer M, Mayr W, Krenn M, Cvecka J, Romanello V, Pietrangelo L, Protasi F, Sandri M, Zampieri S, Musaro A. Electrical stimulation counteracts muscle decline in seniors. Front Aging Neurosci. 2014 Jul 24;6:189. doi: 10.3389/fnagi. 2014.00189.

37 Carraro U, Kern H, Gava P, Hofer C, Loefler S, Gargiulo P, Edmunds K, Árnadóttir ÍD, Zampieri S, Ravara B, Gava F, Nori A, Gobbo V, Masiero S, Marcante A, Baba A, Piccione F, Schils S, Pond A, Mosole S. Recovery from muscle weakness by exercise and FES: lessons from Masters, active or sedentary seniors and SCI patients. Aging Clin Exp Res. 2017 Aug;29(4):579-590. doi: 10.1007/s40520 -016-0619-1.

38. Zampieri S, Mosole S, Löfler S, Fruhmann H, Burggraf S, Cvečka J, Hamar D, Sedliak M, Tirptakova V, Šarabon N, Mayr W, Kern H. Physical exercise in aging: nine weeks of leg press or electrical stimulation training in 70 years old sedentary elderly people. Eur J Transl Myol. 2015 Aug 25;25(4):237-42. doi: 10.4081/ejtm.2015 .5374. eCollection 2015 Aug 24.

39. Kern H, Carraro U. Home-Based Functional Electrical Stimulation of Human Permanent Denervated Muscles: A Narrative Review on Diagnostics, Managements, Results and Byproducts Revisited 2020. Diagnostics (Basel). 2020 Jul 29;10(8):529. doi: 10.3390/diagnostics 10080529.

40. Recenti M, Ricciardi C, Edmunds K, Gislason MK, Gargiulo P. Machine learning predictive system based upon radiodensitometric distributions from mid-thigh CT images. Eur J Transl Myol. 2020 Apr
1;30(1):8892. doi: 10.4081/ejtm.2019.8892. eCollection 2020 Apr 7.

41. Albertin G, Ravara B, Kern H, Hofer C, Loefler S, Jurecka W, Guidolin D, Rambaldo A, Porzionato A, De Caro R, Zampieri S, Pond A, Alaibac M, Carraro $\mathrm{U}$. Two-years of home based functional electrical stimulation recovers epidermis from atrophy and flattening after years of complete Conus-Cauda Syndrome. Medicine (Baltimore). 2019 Dec;98(52):e18509. doi: 10.1097/MD. 0000000000018509.

42. Krenn M, Haller M, Bijak M, Unger E, Hofer C, Kern H, Mayr W Safe neuromuscular electrical stimulator designed for the elderly. Artif Organs. 2011 Mar;35(3):253-6. doi: 10.1111/j.15251594.2011.01217.x.

43. Zampieri S, Pietrangelo L, Loefler S, Fruhmann H, Vogelauer M, Burggraf S, Pond A, Grim-Stieger M, Cvecka J, Sedliak M, Tirpáková V, Mayr W, Sarabon N, Rossini K, Barberi L, De Rossi M, Romanello V, Boncompagni S, Musarò A, Sandri M, Protasi F, Carraro U, Kern H. Lifelong physical exercise delays age-associated skeletal muscle decline. J Gerontol A Biol Sci Med Sci. 2015 Feb;70(2):163-73. doi: 10.1093/Gerona/ glu006. Epub 2014 Feb 18.

44. Glenn WW, Phelps ML. Diaphragm pacing by electrical stimulation of the phrenic nerve. Neurosurgery. 1985 Dec;17(6):974-84. doi: 10.1227/00006123-198512000-00021.

45. Berger D, Bloechlinger S, von Haehling S, Doehner W, Takala J, Z'Graggen WJ, Schefold JC. Dysfunction of respiratory muscles in critically ill patients on the intensive care unit. J Cachexia Sarcopenia Muscle. 2016 Sep;7(4):403-12. doi: 10.1002/jcsm.12108. Epub 2016 Mar 9.

46. Peñuelas O, Keough E, López-Rodríguez L, Carriedo D, Gonçalves G, Barreiro E, Lorente JÁ. Ventilator-induced diaphragm dysfunction: translational mechanisms lead to therapeutical alternatives in the critically ill. Intensive Care Med Exp. 2019 Jul 25;7(Suppl 1):48. doi: 10.1186/s40635-019-0259-9.

47. Marrero HDJG, Stålberg EV, Cooray G, Corpeno Kalamgi R, Hedström Y, Bellander BM, Nennesmo I, Larsson L. Neurogenic vs. Myogenic Origin of Acquired Muscle Paralysis in Intensive Care Unit (ICU) Patients: Evaluation of Different Diagnostic Methods. Diagnostics (Basel). 2020 Nov 18;10(11):966. doi: 10.3390/ diagnostics10110966.

Submitted: January 26, 2021

Revision received: February 23, 2021 Accepted for publication: March 01, 2021 